\title{
Desenvolvimento profissional de um professor ao (re)elaborar uma prova escrita de matemática
}

\author{
Professional development of a teacher to (re) prepare a written \\ mathematics proof
}

Tiago Ponciano Antunes ${ }^{1}$

Marcele Tavares Mendes²

\section{Resumo}

Neste artigo, ancorados em uma avaliação da aprendizagem como prática de investigação e oportunidade de aprendizagem, apresentamos uma discussão acerca da atividade de um professor (re)elaborar uma prova escrita. Subsidiamos nossas reflexões na análise de um ciclo de interação de aplicação de uma tarefa de uma prova escrita - Prova de Levar para Casa, e sua respectiva grelha de correção. Ela foi aplicada a um grupo de 8 alunos do $6^{\circ}$ ano do Ensino Fundamental de uma escola estadual do Paraná na cidade de Londrina no segundo semestre de 2017. Esse ciclo de interação baseia-se na abordagem de Pesquisa em Desenvolvimento (Design Research). Do ponto de vista metodológico, a discussão realizada a partir da análise da produção escrita presente nas provas tem natureza qualitativa e se fundamenta em uma análise interpretativa. A partir desse processo de análise, foi possível inferir que um professor ao (re)elaborar os instrumentos utilizados tem a oportunidade de desenvolver saberes docentes da prática avaliativa (a que ocorreu), assim como para a prática avaliativa (ações futuras); de reconhecer a possibilidade de provocar mudanças na realidade escolar, na direção de envolver os alunos em um processo de avaliação que subsidia e orienta os processos de ensino e de aprendizagem.

Palavras chave: Educação Matemática; Avaliação da Aprendizagem; Análise da Produção Escrita; Prova Escrita; Grelhas de Correção.

\section{Abstract}

In this article, anchored in an assessment of learning as a research practice and learning opportunity, we present a discussion about the activity of a teacher (re) writing a written test. We subside our reflections in the analysis of a cycle of interaction of application of a task of a written test - Proof of Take Home, and its respective grille of correction. It was applied to a group of 8 students from the 6th grade of Elementary School of a state school in the city of Londrina in the second half of 2017. This cycle of interaction is based on the approach of Research in Development (Design Research). From a methodological point of view, the discussion based on the analysis of written production present in the tests is qualitative in nature and is based on an interpretative analysis. From this process of analysis it was possible to infer that a teacher, when (re) elaborating the instruments used, has the opportunity to develop teaching knowledge of the evaluation practice (what happened), as well as to the evaluation practice (future actions); to recognize the possibility of provoking changes in the school reality, in the direction of involving the students in an evaluation that subsidizes and guides the teaching and learning processes.

Keywords: Mathematics Education; Learning Assessment; Written Production Analysis; Written test; Correction Grids.

\footnotetext{
${ }^{1}$ Universidade Tecnológica Federal do Paraná | tiago_ponciano27@hotmail.com

${ }^{2}$ Universidade Tecnológica Federal do Paraná | marceletavares@utfpr.edu.br
} 


\section{Introdução}

O processo de avaliação é uma intervenção presente nas ações escolares de todas as etapas de ensino. Apesar de sua posição relevante, de pesquisas e de nossos documentos nacionais, os Parâmetros Curriculares Nacionais - PCN (BRASIL, 1998) e a Base Nacional Comum Curricular - BNCC (BRASIL, 2017), apresentarem uma pratica avaliativa com o propósito de subsidiar e orientar os processos de ensino e de aprendizagem, a avaliação presente nas escolas tem adotado um caráter verificador de aprendizagens, com intenção primeira de, a partir de uma correção baseada em acertos e erros de uma prova escrita, gerar uma medida (média/nota) que responde se o aluno está aprovado ou reprovado.

$\mathrm{Na}$ busca de (re)pensar caminhos para promover em um contexto de sala de aula um processo de avaliação que esteja a serviço da aprendizagem, pesquisadores da Educação Matemática tem desenvolvido e analisado experiências comprometidas com instrumentos que ressignificam a prova escrita e, em suas discussões, tem apresentado possíveis encaminhamentos (PEDROCHI JUNIOR, 2012; TREVISAN, 2013; MENDES, 2014; FORSTER, 2016).

Buriasco, Ferreira e Ciani $(2009$, p. 7) apontam que não se trata de abandonar a prova escrita, mas sim "deixar de olhá-la como um meio pelo qual se podem obter informações a respeito de como se tem desenvolvido o processo de aprendizagem dos estudantes", para o professor, a partir de uma atitude investigativa, "questionar-se a respeito de qual matemática os seus estudantes estão aprendendo, que entendimentos estão tendo do que está sendo trabalhado em sala de aula, do que já sabem, que dificuldades encontram, e o que pode ser feito para auxiliá-los na superação destas".

Contudo, para exercer essa atitude investigativa, é preciso o professor reconhecer a indissociabilidade dos processos de ensino, de aprendizagem e de avaliação e, reconhecer uma abordagem avaliativa de caráter didático/formativo que depende diretamente da qualidade do instrumento de avaliação e de sua utilização. O processo de elaborar e reelaborar um instrumento de avaliação é uma atividade do professor. Para além de elaborar um instrumento que serve para a certificação e/ou recolha de informações a respeito dos processos de aprendizagem dos estudantes, reconhecemos nessa ação o potencial para o próprio professor construir saberes sobre suas práticas avaliativas, assim como de suas práticas de ensino, para melhor intervir nos processos de aprendizagem dos estudantes, um saber construído na e para a prática letiva.

Neste contexto, interessa-nos investigar como elaborar/reelaborar uma prova escrita possibilita repensar uma prática avaliativa que serve ao processo de aprendizagem? Isto é, interessa-nos discutir o processo de elaboração (design) de tarefas de uma prova escrita enquanto um processo de desenvolvimento de saberes docentes da prática avaliativa (o que ocorreu), assim como para a prática avaliativa (ações futuras).

Nesse artigo especificamente, subsidiamos nossas reflexões na análise de um ciclo de interação de aplicação de uma tarefa de uma prova escrita - Prova de Levar para Casa, e sua respectiva grelha de correção. Ela foi aplicada a um grupo de 8 alunos do $6^{\circ}$ ano do Ensino Fundamental de uma escola estadual do Paraná na cidade de Londrina no segundo semestre de 2017. Esse ciclo de interação baseia-se na abordagem de Pesquisa em Desenvolvimento (Design Research).

Para tanto, apresentamos uma discussão dos resultados e inferências realizadas acerca da questão de investigação, tomando como ponto de partida apresentar e discutir a perspectiva de avaliação considerada. Em seções próprias expomos aspectos dos 
procedimentos metodológicos da pesquisa, em particular do recorte aqui discutido. Em seguida apresentamos e discutimos algumas produções de alunos em uma tarefa de uma Prova de Levar para Casa. Finalizamos com as nossas considerações finais, seguidas das referências bibliográficas.

\section{Avaliação escolar: processo que "alimenta" os processos de ensino e de aprendizagem}

Em termos gerais, avaliar requer um agente avaliador que irá emitir um julgamento, preciso ou não, e um sujeito que será avaliado (BARLOW, 2006). Em contexto de sala de aula, a avaliação deve ir além da emissão de um julgamento, deve direcionar o aluno em uma trilha pedagógica, no sentido de ser utilizada pelo estudante para a construção de seu conhecimento (HADJI, 1994).

Entretanto, práticas avaliativas no contexto da sala de aula têm se restringido a momentos de realização de uma prova escrita. A ação do professor se resume em elaborar e aplicar o instrumento com determinados objetivos prévios e transformar a produção de cada aluno em uma nota ou conceito. Conforme Luckesi (2000), essa ação está ligada à ação de verificação e não à avaliação da aprendizagem. Muito mais que atribuir uma nota ou conceito ao aluno, a avaliação requer ações, estratégias e instrumentos planejados e coerentes ao que se busca avaliar.

A avaliação, para além da verificação, envolve um ato que ultrapassa a obtenção de configuração do objeto, exigindo decisão do que fazer ante ou com ele. A verificação é uma ação que "congela" o objeto; a avaliação, por sua vez, direciona o objeto numa trilha dinâmica de ação (LUCKESI, 2000), logo a avaliação não é uma mera ferramenta estática, pronta e acabada.

O processo avaliativo na escola, mais precisamente na sala de aula é o meio pelo qual se dará os processos de ensino e de aprendizagem. Por meio desse processo, quando realizado com a intenção de obter informações sobre as próprias ações (do professor), os dados e informações coletados e observados (dos alunos) ao longo do processo serve como ponto de partida para se fomentar a respeito de ambos os processos (ensino e aprendizagem).

Para De Lange (1999), a avaliação requer responsabilidade por parte dos professores. Tendo eles a oportunidade de observar os alunos e ver o reflexo de suas práticas, passam a conhecer as necessidades de adaptações e modificações ao olhar para dentro de si e reconhecer suas limitações enquanto professor que exerce papel de agente avaliador, mas essas limitações podem ser superadas ao criar possibilidades de reflexão sobre suas ações.

A responsabilidade do professor se faz presente e necessário ao processo avaliativo diante da necessidade da articulação do agente avaliador (professor) e do sujeito a ser avaliado (aluno). O professor não é apenas responsável por elaborar tarefas e instrumentos de avalição, mas em conduzir as aulas, fazer uso de abordagens e metodologias para os conteúdos. Cabe ao seu papel repensar sobre suas ações e identificar ajustes necessários para que possa desempenhar um papel de avaliador que não se distancie do papel de professor, uma vez que o processo avaliativo precisa ser conduzido por ele.

Em uma prática avaliativa em que o professor se distancia do avaliador, consequentemente irá distanciar o processo de ensino do processo de aprendizagem, 
resultando assim, de acordo com Luckesi (2000), em um processo de verificação do sujeito. Nesse contexto o avaliador não tem pretensão de refletir sobre suas ações, mas sim observar e julgar o sujeito diante de seus objetivos pré-estabelecidos e tentar enquadrá-los sem nenhuma outra possibilidade a não ser o certo ou errado.

Portanto, para que um processo avaliativo possa ser reconhecido como aquele que alimenta tomadas de decisão é preciso fazer uso de ferramentas avaliativas que possibilitem ao professor, que também é o agente avaliador, refletir sobre sua prática pedagógica, mas que ao mesmo tempo possibilite aos sujeitos (alunos) apresentarem informações coerentes ao processo.

\section{Educação matemática realística: um olhar para a avaliação didática}

No final da década de sessenta, na Holanda, por meio de uma reforma na Educação Matemática, iniciou-se o desenvolvimento da Educação Matemática Realística (RME), que é uma abordagem para o ensino de matemática cujo precursor foi Freudenthal (1905 -1990).

Mendes (2014) relaciona aspectos tomados por Freudenthal em relação às tendências tradicionais de ensino conforme apresentado no Quadro 1.

Quadro 1 - Aspectos para ensino da matemática na RME em relação a Tendências Tradicionais

\begin{tabular}{|l|l|}
\hline \multicolumn{1}{|c|}{ RME } & \multicolumn{1}{|c|}{ Tendências Tradicionais } \\
\hline Atividade humana & Disciplina preestabelecida \\
\hline Matematização da realidade & Realidade matematizada \\
\hline Reinvenção de conceitos & Transmissão de conceitos \\
\hline Realidade como fonte da matemática & Realidade como domínio de aplicação \\
\hline Articulação da matemática com outros domínios & Matemática isolada \\
\hline Contextos ricos de significado & Reunião de problemas linguísticos \\
\hline Elaboração de representações mentais & Conceitos \\
\hline Compreensão de mecanismos & Reprodução de mecanismos \\
\hline Abordagens múltiplas em relação a conceitos & Concretização múltipla \\
\hline novos & \\
\hline
\end{tabular}

Fonte: (MENDES, 2014, p. 23).

Apesar de mudanças significativas, por meio da reforma que se iniciava nos anos sessenta, referente à maneira de ensinar e de aprender os conteúdos de Matemática nas salas de aula, pouco (ou nada) se discutia referente a mudanças no processo de avaliação da aprendizagem até os anos oitenta na Holanda. Somente no início dessa década, simultaneamente à reforma do currículo de matemática do ensino secundário, buscou-se iniciar uma discussão acerca de uma avaliação adequada para garantir as mudanças curriculares pretendidas (VAN DEN HEUVEL-PANHUIZEN, 1996). 
Essa avaliação tinha a finalidade de servir ao ensino e à aprendizagem e foi denominada Avaliação Didática. De acordo com Van den Heuvel-Panhuizen (1996, p. 11), a Avaliação Didática objetiva ser um "apoio ao processo de ensino e de aprendizagem". Ela está intimamente ligada à instrução e, em princípio, é parte da prática educacional diária, ou seja, serve às ações práticas do cotidiano do professor, elaborar/escolher um instrumento de avaliação, preparar novas práticas de ensino para os conteúdos, como correções etc.

A Avaliação Didática, enquanto processo, reconhecida na ação diária e de natureza didática, se estende para além do espaço da sala de aula e do ato de aplicar uma prova escrita, corrigir e atribuir uma nota. O objetivo da avaliação da sala de aula é "produzir informações que contribuam para o ensino e processo de aprendizagem e auxiliem na tomada de decisões educacionais, em que os tomadores de decisão incluem estudantes, professores, pais e administradores" (DE LANGE, 1999, p. 3).

Por outro lado, apesar de concordarmos que avaliar não restringe a corrigir uma prova escrita, reconhecemos o potencial desse instrumento em gerar informações para subsidiar os processos de ensino e de aprendizagem ao professor realizar por meio dela uma prática avaliativa investigativa. Uma "avaliação constituída como um processo que indaga os resultados apresentados, os trajetos percorridos, os percursos previstos, as relações estabelecidas entre as pessoas, saberes, informações, fatos, contextos (ESTEBAN, 2003, p. 11).

A Prova Escrita, elaborada para ser resolvida individualmente, sem consulta a materiais de apoio e com tempo limitado (prova em uma fase), é o instrumento mais recorrente nas práticas avaliativas em aulas de matemática. Van den Heuvel-Panhuizen (1996), apresenta outras configurações para a prova escrita que podem ser explorados como estratégias para aumentar o potencial da tradicional prova escrita.

A Prova de Ensaio é um texto literário breve, que expõe ideias, críticas e reflexões a respeito de um determinado tema. Como um instrumento de avaliação em matemática, os alunos podem ser convidados a escrever respondendo a um artigo de jornal, ou dar a sua opinião sobre alguma situação da vida cotidiana (VAN DEN HEUVEL-PANHUIZEN, 1996). Com esse instrumento, pode-se analisar a capacidade do aluno de elaborar argumentações matemáticas acerca de algum conteúdo por meio de um tema quotidiano como por exemplo gráficos e tabelas em revistas e jornais. Quando o aluno expõe suas ideias, suas reflexões, isso possibilita ao professor conhecer como ele (o aluno) percebe a matemática. Em um ensaio, o aluno é capaz de fazer apontamentos que, muitas vezes, não consegue em uma prova escrita tradicional por possui liberdade de argumentar, expor suas ideias, levantar apontamentos, fazer crítica, elaborar hipóteses, fazer suposições, o que o leva a repensar a própria matemática.

A Prova De Levar para Casa consiste em uma prova escrita elaborada pelo professor a respeito de um ou mais conteúdo. Esse instrumento possibilita que o aluno leve a prova para resolver as tarefas em casa, com mais tempo, utilizando quaisquer materiais de apoio ou até mesmo pedindo ajuda a outras pessoas (VAN DEN HEUVEL-PANHUIZEN, 1996). Com esse instrumento, o professor pode obter informações sobre como os alunos lidam com os conteúdos e como buscam as informações necessárias para resolvê-los, seja por meio de pesquisas na Internet, seja em livros, cartilhas, seja tirando dúvidas com os pais ou familiares. Esse instrumento de avaliação também proporciona ao aluno maior liberdade para buscar e estudar de maneira autônoma a fim de que possa resolver as tarefas. 
A Prova em Duas Fases (DE LANGE, 1987) é um instrumento de avaliação que combina vários formatos de provas escritas. Inicialmente, o professor deve deixar claro para os alunos como será cada uma das fases. A primeira fase se dá na sala de aula, durante um período de tempo preestabelecido. O instrumento pode conter um número maior de tarefas, uma vez que é possível resolvê-las em duas fases. O professor então recolhe as provas e realiza a correção das tarefas e, nesse momento, pode identificar as dificuldades, os erros comuns, além da diversidade de estratégias utilizadas para resolvê-las.

Como se trata de uma prova escrita, o docente pode fazer anotações nas tarefas dos alunos respeitando as particularidades de cada produção, tendo em vista o aprimoramento do conceito abordado, que poderá ser reformulado, ou até mesmo corrigido pelo aluno na segunda fase. A segunda fase consiste em entregar novamente a prova, agora corrigida e com regulações escritas, para que os alunos refaçam o que achar necessário, além de fazer o que não tinham conseguido na primeira fase. O professor pode até mesmo retomar algum conteúdo que apresentou maior dificuldade para os alunos. Ele estabelece um determinado período de tempo para os alunos refazerem a prova, depois corrige novamente as tarefas levando em conta o que eles haviam feito na primeira fase. Esse momento serve para observar indícios de que os alunos progrediram, ou de que partiram de conceitos simples para conceitos mais elaborados.

A Prova de Produção consiste em solicitar que os alunos elaborem suas provas escritas com as respectivas tarefas (VAN DEN HEUVEL-PANHUIZEN, 1996). O professor pode reorganizar a sala de aula em grupos menores para melhor acompanhar 0 encaminhamento. Em seguida, os grupos trocam as provas e cada um, agora com uma prova diferente, resolve as tarefas solicitadas. Após um tempo preestabelecido, as provas resolvidas voltam para os grupos que as elaboraram, e assim podem fazer a sua correção. Esse movimento de elaborar e corrigir uma prova possibilita aos alunos um momento de autonomia e criação, colocando em prática os conteúdos elaborados. Nesse momento, os estudantes podem pedir auxílio ao professor, ou mesmo se apoiar em algum material didático pertinente. Posteriormente, o professor faz uma análise das tarefas elaboras pelos grupos e das respectivas correções, observando a coerência entre o conteúdo e as tarefas e, consequentemente, se foram corrigidas adequadamente. Isso leva o professor ter indícios do que os alunos consideram como correto, ou como incorreto. Ao final, o professor pode dar um feedback de todas as provas para os alunos.

A Prova Em Grupo consiste em uma prova escrita para a qual o professor elabora as tarefas de acordo com os conteúdos trabalhados em sala de aula. O professor informa os alunos de que podem fazer grupos compostos de $n$ alunos, de acordo com a quantidade de alunos da turma, e estabelece o período de tempo para a sua aplicação. O professor pode, ainda, solicitar que os grupos resolvam em conjunto, mas cada aluno apresenta uma justificativa para a resolução do seu grupo, assim é possível verificar se todos concordam com a resolução, se houve debates para chegar a uma resposta comum. Esse momento de interação dos grupos possibilita que os alunos expressem seu pensamento matemático, estratégias e possível domínio de conceitos mais elaborados, assim os demais alunos passam a ter contato com todos esses aspectos.

O caráter didático desses instrumentos pode ser reconhecido de acordo com as especificidades e características de cada um. Em particular, pode-se observar uma característica comum a todos: utilizar uma prova escrita. Com a possibilidade de resolver de maneira discursiva, os alunos podem deixar seu registro e, com isso, deixar evidências de 
estratégias, métodos de resolução, evidências de dificuldades em relação aos conteúdos e/ou conceitos, além de uma diversidade de informações que podem ser utilizadas pelo professor como ponto de partida para reflexões de sua prática avaliativa.

\section{Grelhas de correção: uma oportunidade de reflexão}

O termo "grelha" remete a algum tipo de utensílio em forma de grade que é utilizado para aparar, apoiar e/ou sustentar algum objeto. No contexto de avaliação, a palavra não é frequente, quase não é utilizada. No livro de Hadji (1994), porém, intitulado "A avaliação, regras do jogo: das intenções aos instrumentos", é possível evidenciar esse termo voltado aos processos avaliativos.

Ao elaborar Grelhas de Correção para as respectivas provas escritas, o professor realiza um planejamento prévio e coloca em prática ações que podem contribuir para uma prática pedagógica coerente.

Hadji (1994) descreve, em termos de uma avaliação observável de uma realidade, a realidade do sujeito avaliado pelo agente avaliador. Se a avaliação é algo observável, é preciso que o avaliador utilize um instrumento de apoio que lhe permita "filtrar" as inúmeras situações que observa, mas também é preciso que essa observação seja previamente delimitada e planejada, ou seja, a observação deverá partir de um instrumento já elaborado. Dessa forma, o avaliador observa à luz desse instrumento.

Para esse autor, o instrumento é uma grelha, e afirma que "o ato de avaliar é um ato de 'leitura' de uma realidade observável, que aqui se realiza com uma grelha predeterminada, e leva a procurar, no seio dessa realidade, os sinais que dão o testemunho da presença dos traços desejados" (HADJI, 1994, p. 31).

Ante esse contexto, as grelhas de correções, bem como a análise das produções escritas dos alunos presentes em uma prova escrita, permitem ao professor refletir sobre a prática avaliativa ao utilizar-se de uma diversidade de instrumentos reconfigurados de uma prova escrita tradicional. As reflexões do professor podem tornar a avaliação mais próxima de uma que reflete diretamente na prática e para a prática de ensino e vice-versa.

\section{Encaminhamento metodológico}

Esse artigo é um recorte de uma pesquisa de mestrado que teve como método de coleta de dados a Design Based Research (DBR). Neste método a coleta de dados se dá por iterações compostas por ciclos, onde cada ciclo é composto por um design, implementação e análise, como mostra a Figura 1.

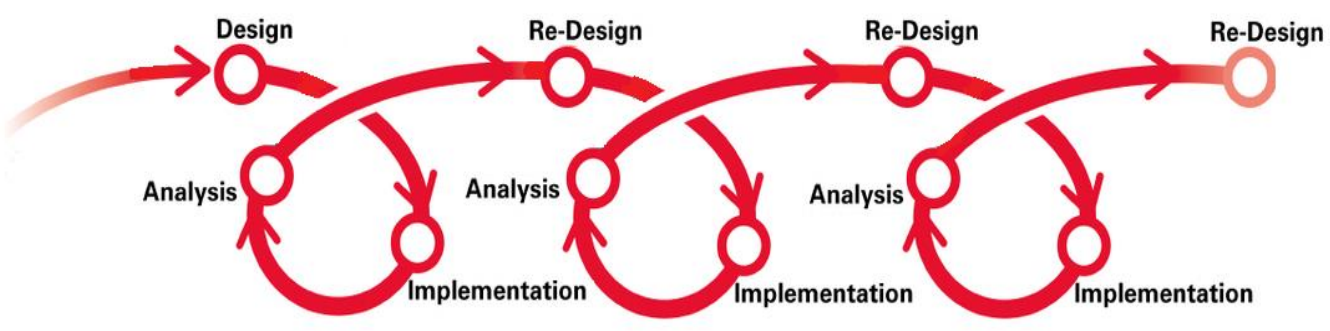

Figura 1 - Ciclos da DBR baseado em Matta, Silva e Boaventura (2014). 
A Design Based Research (DBR), de acordo com Matta, Silva e Boaventura (2014),

[...] é uma inovadora abordagem de investigação que reúne as vantagens das metodologias qualitativas e das quantitativas, focalizando no desenvolvimento de aplicações que possam ser realizadas e de fato integradas às práticas sociais comunitárias, considerando sempre sua diversidade e propriedades específicas, mas também aquilo que puder ser generalizado e assim facilitar a resolução de outros problemas (MATTA; SILVA; BOAVENTURA, 2014, p. 24).

Na pesquisa de mestrado foram desenvolvidos três ciclos de iteração. Os instrumentos, sujeitos envolvidos em cada um dos ciclos estão descritos no Quadro 2. O conteúdo abordado contemplado nas tarefas de cada instrumento referiu-se a plantas baixas, bem como a conceitos de área e perímetro. A abordagem dos conteúdos se deu por uma Trajetória de Ensino e de Aprendizagem ${ }^{3}$ à luz da Educação Matemática Realística pelo professor regente da turma.

A discussão desse artigo foi baseada em uma tarefa desenvolvida no primeiro ciclo de iteração, composto pela elaboração de uma Prova de Levar para Casa de matemática, aplicação e análise da produção escrita dos alunos e por fim as reflexões diante da aplicação de uma prova escrita de matemática em um contexto avaliativo.

Uma vez considerado o saber docente como plural, oriundo da formação profissional e de saberes disciplinares curriculares e experienciais, sendo estes últimos construídos durante o exercício da profissão, e durante sua experiência como aluno em toda a vida escolar (TARDIF, 2013), buscou-se discutir a prática de refletir sobre seus processos avaliativos uma oportunidade de construção de novos saberes, em especial saberes a respeito da avaliação da aprendizagem.

Para o primeiro ciclo, foi elaborado um instrumento de avaliação Prova de Levar para Casa. $O$ instrumento foi aplicado, no fim de uma Trajetória de Ensino e de Aprendizagem (TEA) em uma turma regular do $6^{\circ}$ "B" de uma escola pública do município de Londrina-PR. Oito (8) alunos se dispuseram a realizar em contraturno a aplicação da TEA e lidar com o instrumento de avaliação Prova de Levar para Casa. A TEA desenvolvida e aplicada pelo professor da turma envolvia plantas baixas, área e perímetro de figuras planas. Do mesmo modo, desenvolvemos as tarefas para compor o instrumento Prova de Levar para Casa.

Os dados coletados, para análise a partir do lidar dos alunos com cada uma das tarefas da Prova de Levar para Casa, foram o registro no diário do professor, a produção escrita dos alunos. Os alunos, pais e direção da escola assinaram um termo de consentimento livre e esclarecido para utilização e divulgação dos dados. Para realizar a correção da primeira tarefa que compunha o instrumento Prova de Levar para Casa, os alunos foram inicialmente

\footnotetext{
${ }^{3}$ O desenvolvimento e aplicação dessa TEA são objetos de outra pesquisa de mestrado sob orientação da segunda autora desse texto. Em uma TEA há uma visão geral dos processos de aprendizagem dos estudantes; indicações didáticas que descrevem um ensino que articula e estimula a aprendizagem; um esboço do assunto do currículo de matemática a ser ensinado (VAN DEN HEUVEL-PANHUIZEN, 1996).
} 
renomeados por "ALN1_", em que "ALN" corresponde ao aluno, "1" à primeira aplicação e "." a uma letra do alfabeto. Ao se referir ao aluno "A", por exemplo, ficará como "ALN1A".

Quadro 2 - Descrição dos três Ciclo Iterativo de Aplicações.

\begin{tabular}{|c|c|c|}
\hline \multirow{12}{*}{ 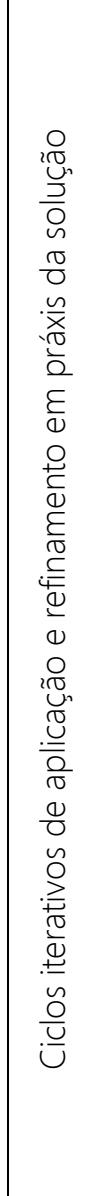 } & $\begin{array}{l}\text { Implementação da } \\
\text { intervenção (primeira } \\
\text { iteração). }\end{array}$ & $\begin{array}{l}\text { Prova de Levar para Casa na Escola onde o professor } \\
\text { colaborador da pesquisa trabalha e aplica uma Trajetória de } \\
\text { Ensino e de Aprendizagem. }\end{array}$ \\
\hline & Participantes. & $\begin{array}{l}\text { Oito alunos de } 6^{\circ} \text { ano do Ensino Fundamental de turmas em } \\
\text { que o professor colaborador da pesquisa não atua como } \\
\text { professor (atividade contraturno). }\end{array}$ \\
\hline & Coleta de informações. & Produção escrita dos alunos. \\
\hline & Análise das informações. & Análise da Produção Escrita. \\
\hline & $\begin{array}{l}\text { Implementação da } \\
\text { intervenção (segunda } \\
\text { iteração). } \\
\end{array}$ & Prova em Grupo após a reformulação da primeira iteração. \\
\hline & Participantes. & $\begin{array}{l}\text { Uma turma de } 6^{\circ} \text { ano do Ensino Fundamental de } 30 \text { alunos } \\
\text { na qual o professor colaborador da pesquisa atua como } \\
\text { professor. }\end{array}$ \\
\hline & Coleta de informações. & Produção escrita dos alunos. \\
\hline & Análise das informações. & Análise da Produção Escrita. \\
\hline & \begin{tabular}{|lr} 
Implementação & da \\
intervenção & (terceira \\
iteração). & \\
\end{tabular} & $\begin{array}{l}\text { Prova escrita em duas fases após reformulação da segunda } \\
\text { iteração. }\end{array}$ \\
\hline & Participantes. & $\begin{array}{l}\text { Uma turma de } 6^{\circ} \text { ano do Ensino Fundamental de } 30 \text { alunos } \\
\text { na qual o professor colaborador da pesquisa atua como } \\
\text { professor. }\end{array}$ \\
\hline & Coleta de informações. & Produção escrita dos alunos. \\
\hline & Análise das informações. & Análise da produção Escrita. \\
\hline
\end{tabular}

O Quadro 3 apresenta o enunciado da tarefa analisada da Prova de Levar para Casa, bem como a sua grelha de correção. Esta tarefa teve por objetivo que os alunos reconhecessem os conceitos de uma planta baixa, que eles interpretassem as informações do enunciado. Além disso, objetivou que os alunos reconhecessem a necessidade da utilização dos conceitos de área e perímetro.

A análise da produção escrita foi o recurso utilizado para identificar e discutir a(s) estratégia(s) e o(s) procedimento(s) escolhido(s) por cada aluno na resolução da tarefa. Por meio dela, buscou-se refletir sobre o formato de cada tarefa, o número de itens que compôs o instrumento, as possíveis interpretações que os alunos tiveram, as mudanças necessárias. Nesse processo a reflexão voltou-se a buscar elementos que poderiam favorecer repensar sobre suas práticas (ações que ocorreram), assim como novas possibilidades para da prática avaliativa que está por vir (ações futuras).

Segundo Smith, Hillen e Heffernan (2001), a análise da produção escrita dos estudantes pode ser utilizada pelos professores na direção de obter um entendimento dos modos como os estudantes estão pensando e representando a matemática. Esses autores assinalam que, se os professores forem capazes de interpretar e entender os modos que os estudantes pensam e representam a matemática, eles podem utilizar estratégias de ensino sobre esses entendimentos, como também, ajudar os alunos a fazer conexões entre suas 
representações idiossincráticas e aquelas mais convencionais (SMITH; HILLEN; HEFFERNAN, 2001, p. 65).

Quadro 3 - Tarefa 1 da Prova de Levar para Casa e sua Grelha de Correção.

1- Utilizando lápis e régua, desenhe a planta baixa de uma casa de acordo com as informaç̃̃es a seguir. Cada centímetro no desenho representa um metro de comprimento da casa.

A área total da casa representada na planta baixa possui $72 \mathrm{~m}^{2}$.

Dois quartos possuem paredes de lados medindo $4 \mathrm{~m}$ e $3 \mathrm{~m}$.

O banheiro não está localizado em nenhum dos quartos, possui medidas de lados iguais, cuja área é $4 \mathrm{~m}^{2}$. Após desenhar a planta baixa, responda os itens da questão

Uma possivel solução:

Área Total $=72 \mathrm{~m}^{2}$

Área Total $=$ Base $\times$ Altura

Área Total $=9 \mathrm{~m} \times 8 \mathrm{~m}$ ou $8 \mathrm{~m} \times 9 \mathrm{~m}$

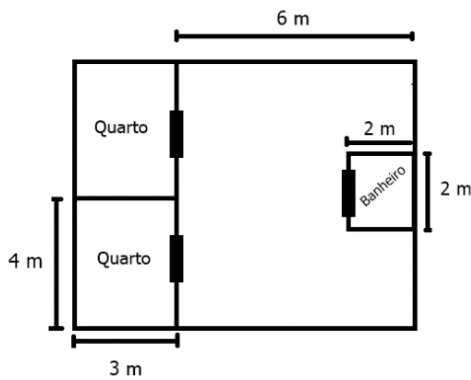

Grelha de correção da Tarefa 1

\begin{tabular}{l|l} 
Classificação & Critérios de correção \\
\hline
\end{tabular}

- O aluno apresenta o desenho de uma planta baixa cujas dimensões são $9 \mathrm{~m} \times 8 \mathrm{~m}$ ou $8 \mathrm{~m} \times 9 \mathrm{~m}$.

Correto $\quad$ - O aluno apresenta na planta baixa os cômodos definidos no enunciado: dois quartos de dimensões $4 \mathrm{~m} \times 3 \mathrm{~m}$ e o banheiro cuja área é $4 \mathrm{~m}^{2}$.

\begin{tabular}{l|l}
\hline - O aluno não retira corretamente os dados do enunciado. \\
- O aluno apresenta o desenho de uma planta baixa, mas com dimensões
\end{tabular}

Parcialmente não correspondentes ao enunciado.

Correto $\quad$ - O aluno apresenta os cômodos, mas com dimensões não correspondentes ao enunciado.

\begin{tabular}{|l|l}
\hline & - O aluno não apresenta nenhuma solução e/ou deixa a tarefa em branco.
\end{tabular}
- Apresenta uma solução qualquer, sem nenhuma relação com a tarefa.

O Quadro 4 apresenta a classificação em relação aos critérios de correção já estabelecidos na grelha.

Quadro 4 - Classificação da produção dos alunos na Tarefa 1.

\begin{tabular}{|l|l|}
\hline Aluno & Classificação \\
\hline ALN1A & Correto \\
\hline ALN1B, ALN1C, ALN1D, ALN1E, ALN1F & Parcialmente Correto \\
\hline ALN1G, ALN1H & Incorreto (branco) \\
\hline
\end{tabular}

Neste contexto, investigamos elementos que emergem do elaborar, aplicar e analisar um instrumento de avaliação, assim como as produções escritas dos alunos e que podem favorecer uma reflexão e construção de saberes docentes referente a uma prática avaliativa que subsidia e orienta a prática pedagógica do professor. 


\section{A utilização da prova de levar para casa: reflexões}

A Prova de Levar para Casa elaborada era composta de duas questões conforme apresentado no Quadro 5. Os alunos puderam levar a prova para suas casas e trazer quatro dias depois, esse período foi definido pelo professor regente.

Quadro 5 - Questões da Prova de Levar para Casa.

1. Utilizando lápis e régua, desenhe a planta baixa de uma casa de acordo com as informações a seguir.

- Cada centímetro no desenho representa um metro de comprimento da casa.

- A área total da casa representada na planta baixa possui $72 \mathrm{~m}^{2}$.

- Dois quartos possuem paredes de lados medindo $4 \mathrm{~m}$ e $3 \mathrm{~m}$.

- O banheiro não está localizado em nenhum dos quartos, possui medidas de lados iguais, cuja área é $4 \mathrm{~m}^{2}$.

- Após desenhar a planta baixa, responda os itens da questão 2.

2. Após desenhar a planta baixa e os cômodos definidos responda:

Observação: Apresente os cálculos e as justificativas.

a) A planta baixa representada anteriormente possui dois quartos e um banheiro definidos. Qual é a área restante desta casa representada na planta baixa?

b) Qual é a área total utilizada nos cômodos que estão definidos, ou seja, os dois quartos e o banheiro?

c) Qual é o perímetro externo da casa representada pela planta baixa?

Após a aplicação e análise da Tarefa 1, as produções dos alunos foram agrupadas por similaridades de resolução. No Quadro 6, consta uma síntese da análise da produção dos alunos.

Quadro 6 - Enunciado, objetivos e análise da produção dos alunos referentes à Tarefa 1.

Análise da produção dos alunos a partir do enunciado da tarefa:

- Quatro dos oito alunos apresentaram a construção de uma planta baixa sem a utilização de régua ou outro instrumento de medição, as dimensões apresentadas na planta baixa não corresponderam às medidas do enunciado.

- Um aluno apresentou apenas a construção dos cômodos e não apresentou a construção da planta baixa completa.

- Um aluno apresentou a construção de uma planta baixa com o auxílio de régua ou outro instrumento de medição, com as dimensões correspondentes ao enunciado.

- dois alunos não apresentaram solução.

Avaliação do enunciado da tarefa a partir da produção dos alunos:

A partir da produção dos alunos, viu-se a necessidade de acrescentar no enunciado da Tarefa que eles escrevessem de alguma forma como pensaram para desenhar a planta baixa, uma vez que nenhuma produção apresentou esse tipo de informação.

Alterações julgadas necessárias após a primeira aplicação:

Algumas adaptações foram necessárias para questionar os alunos sobre o que eles entendem por uma planta baixa, se utiizaram algum material de apoio, se utilizaram régua ou outro instrumento de medição, se resolveram em grupo. 


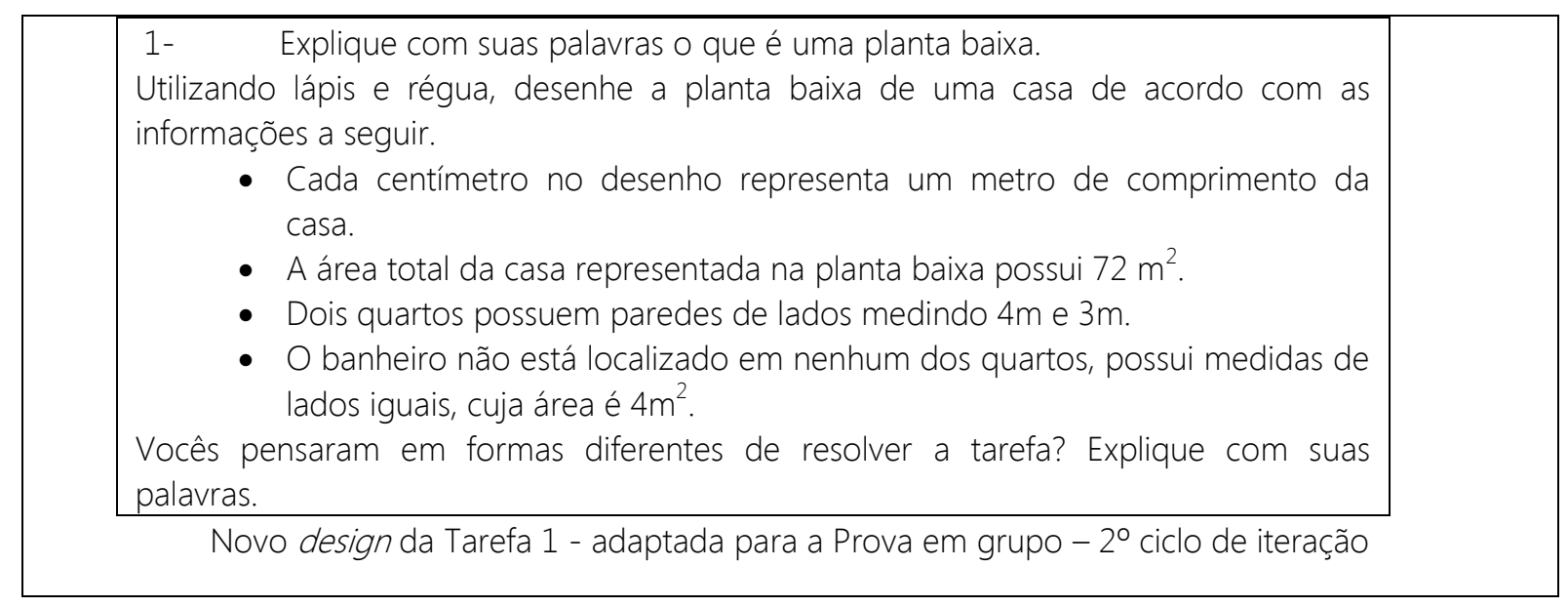

Elaborar um instrumento de avaliação para um determinado conteúdo que está sendo trabalhado na sala de aula (ou foi trabalhado) é uma atividade que requer mais do que escolher as tarefas que irão compô-lo, é uma atividade reflexiva sobre o desenvolvimento dos alunos nas tarefas de instrução (aquelas que o professor utiliza em sala de aula). Conforme Van den Heuvel-Panhuizen (1996), as tarefas de avaliação não devem se distinguir das tarefas de instrução. Essa atividade reflexiva favorece ao professor identificar como e quais tarefas irão exigir do aluno uma produção que vai além do reproduzir o que foi desenvolvido em sala, mas que não serão tarefas que demandem habilidades e competências matemáticas ainda não desenvolvidas, essas tarefas serão o meio do aluno revelar o que sabe.

A abordagem dos conceitos por trás da construção e representação de plantas baixas, ou seja, área, perímetro, escalas, faz parte do currículo escolar, e a Tarefa 1 oportuniza esses objetivos do currículo. De acordo com De Lange (1999), uma tarefa deve oportunizar ao aluno decodificar, interpretar, compreender e traduzir a linguagem matemática, seja ela natural, simbólica ou formal. Um exemplo disso é a produção do aluno ALINA que apresenta a construção de uma planta baixa com indícios de utilização da régua ou de outro instrumento de medição. A produção revela que o aluno retirou corretamente os dados do enunciado, o que indica compreensão das linguagens matemáticas presentes.

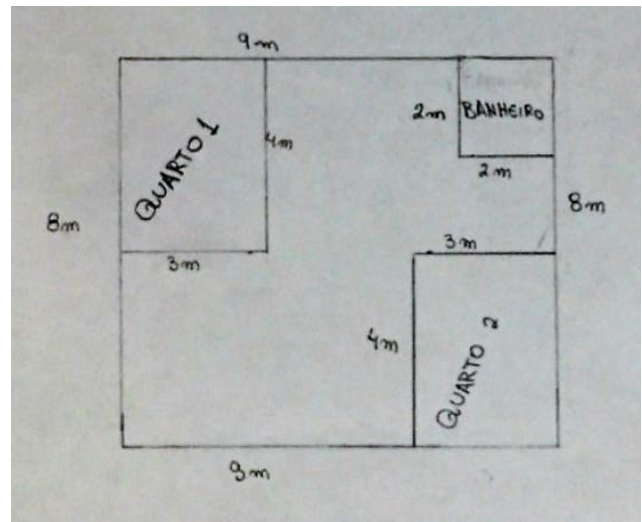

Figura 2 - Produção escrita do aluno ALN1A referente à Tarefa 1.

A produção desse aluno apresenta ainda paredes de dimensões $9 \mathrm{~m}$ por $8 \mathrm{~m}$, o que corresponde a uma área de $72 \mathrm{~m}^{2}$. Apresenta também o desenho dos cômodos definidos, ou seja, dois quartos de dimensões $4 \mathrm{~m} \times 3 \mathrm{~m}$ e um banheito que não está nos quartos, cuja 
dimensão é $2 m \times 2 m$. Essa produção também dá indícios de interpretação e tradução da linguam matemática em suas diversas representações, conforme sugere ser desável De Lange (1999).

Por outro lado, o aluno ALN1B também apresenta o desenho de uma planta baixa, mas por meio de uma régua verificamos que as dimensões utilizadas correspondem a $10 \mathrm{~cm}$, não utilizando medidas que resolvem o problema, uma planta de $72 \mathrm{~m}^{2}$. A produção revela, ainda, que, em relação aos cômodos, o aluno utiliza, em alguns momentos, a régua; em outro momentos, não. Chega-se a essa conclusão porque algumas medidas são as mesmas do enunciado: quartos de $4 \mathrm{~m}$ por $3 \mathrm{~m}$. Pode-se observar também, na produção desse aluno, que ele apresenta um lado da parede externa medindo $18 \mathrm{~m}$, o que equivale a soma de todos as medidas representadas no desenho $(3 m+3 m+4 m+4 m+2 m+2 m)$.

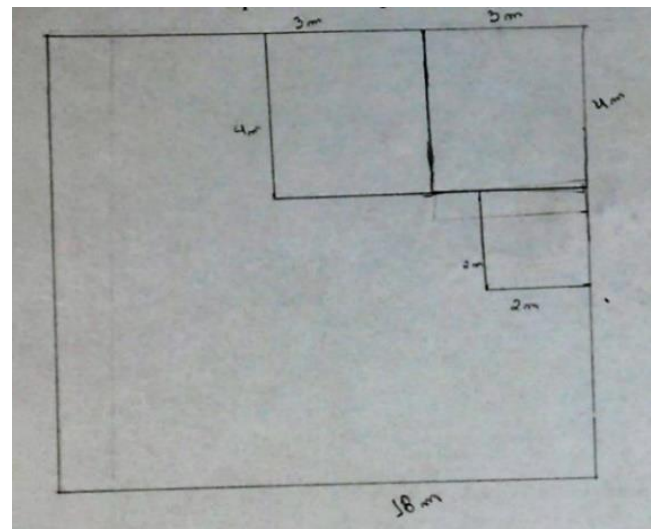

Figura 3 - Produção escrita do aluno ALN1B referente à Tarefa 1.

O aluno ALN1B realizou a produção apresentada na Figura 7, ele dividiu o valor de 72 por 4, obtendo o resultado 18 . Isso evidencia como surgiu o valor $18 \mathrm{~m}$ indicado na parede externa da produção apresentado na Figura 6, que não está de acordo com a primeira inferência do professor. Ainda, como forma de verificar o seu cálculo de divisão, soma esse valor quatro vezes.

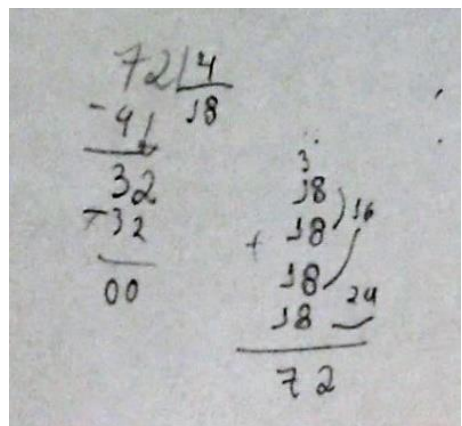

Figura 4 - Produção escrita do aluno ALN1B referente à Tarefa 1.

Essa produção dá indicios de que o aluno partiu da estratégia que sua planta baixa iria representar uma região quadrada, o que é um ponto de partida correto. Entretanto, o procedimento que ele utilizou não resolve o problema, para obter a forma quadrada era preciso determinar um número que elevado ao quadrado resulta em 72. A partir dessa produção o professor pode retomar o conceito de perímetro, de área de uma uma região quadrangular. 
Conforme De Lange (1999), um instrumento de avaliação deve ter potencial para revelar o que os alunos sabem, para além daquilo que eles não sabem. Nessa produção, é possível reconhecer que o aluno ALN1B sabe realizar o procedimento de divisão e reconhe a soma como um processo de prova real. O professor tem a oportunidade de reconhecer que o aluno aproxima o conceito de área do de perímetro, podendo planejar intervenções para lidar com esse conceito. Assim, o professor coloca a avaliação a serviço dos processos de ensino e de aprendizagem.

Elaborar um instrumento de avaliação é uma tarefa complexa. Envolve a articulação dos conteúdos abordados, o nível de ensino em que será aplicado, o tempo de que os alunos dispõem para resolver as tarefas, a quantidade de tarefas que contemplam os conteúdos propostos. Em resumo, esses aspectos são frequentes na prática avaliativa de professores que utilizam um instrumento corriqueiro de avaliação, logo, utilizar uma nova configuração do instrumento Prova Escrita demanda ações a serem consideradas e refletidas pelo docente a fim de que essas ações subsidie os processos de aprendizagem.

O instrumento Prova de Levar para Casa, aqui reconfigurado de uma Prova Escrita tradicional, levou o professor/avaliador a refletir sobre as ações que teve durante a elaboração, a aplicação e a correção das tarefas. As produções escritas dos alunos evidenciaram que as tarefas podem ser refinadas no que diz respeito aos alunos explicitarem a forma como interpretaram a situação proposta. Dentre as oito provas, duas delas não apresentam nenhuma resolução, nem ao menos uma justificativa discursiva, mas isso não pode servir como base para afirmar que o aluno não sabe os conteúdos e/ou conceitos abordados. É preciso, também, que esteja explícito no enunciado que eles podem apresentar e explicar com suas próprias palavras como pensaram para resolver a tarefa.

Uma reconfiguração dessa tarefa foi considerada necessária para questionar os alunos sobre o que eles entendem por uma planta baixa, e também se utilizaram algum material de apoio, se utilizaram régua ou outro instrumento de medição e se resolveram em grupo. Esse tipo de regulação, com questionamentos escritos nas próprias tarefas do instrumento de avaliação Prova de Levar para Casa, pode possibilitar ao aluno refletir sobre a tarefa em diversos aspectos e não apenas para apresentar uma resolução correta, o que dá ao aluno a possibilidade de expressar-se sobre os conceitos abordados sem categorizá-los como certos ou errados. Dessa forma, o professor pode também refletir sobre os intrumentos e tarefas elaborados e trazer novas e necessárias modificações a um futuro instrumento de avaliação, favorecendo uma prática formativa.

O momento de elaborar e (re)elaborar (design) uma prova escrita muitas vezes é visto como algo simples, mesmo sendo um dos instrumentos mais utilizados pelos professores. Os professores, na maioria das vezes, selecionam tarefas similares que foram trabalhadas em sala durante a abordagem do conteúdo para que os alunos reproduzam, fielmente, os algoritmos de simples memorização e reprodução.

Entretanto, lidar com o processo de (re)desenhar provas escritas de matemática e com as tarefas inseridas nesse instrumento é uma ação que exige do professor um discernimento entre "avaliação" e "prova". É necessário articular tarefas que tenham similaridade com as trabalhadas em sala de aula, porém também é necessário apresentar aos alunos tarefas que demandem refletir sobre os conteúdos matemáticos, ou repensá-los, para ultrapassar a simples reprodução.

Contudo, elaborar um bom instrumento de avaliação, ressignificado de provas escritas tradicionais, é apenas uma parte de todo o processo avaliativo. O fato de os professores 
não encontrarem uma resposta para certas inquietações ("O que é avaliar?", por exemplo), ou mesmo de internalizar a crença de que "avaliação" e "prova" são sinônimos, muitas vezes acaba limitando-os a recorrer às mesmas práticas avaliativas durante anos.

O processo avaliativo como um todo é baseado em ações que o norteiam. Tais ações dizem respeito ao processo de elaboração de um bom planejamento, à forma como o professor observa as dificuldades dos alunos, como lida com essas dificuldades durante o processo avaliativo, o que faz para superá-las, como elabora e reelabora um instrumento de avaliação, como utiliza a diversidade de instrumentos a favor da aprendizagem dos alunos, como lida com as correções das provas escritas e como utiliza todos esses elementos como fonte de reflexão de seu trabalho pedagógico enquanto professor.

Todas essas ações remetem a um processo de avaliação caracterizado como um processo que serve aos processos de ensino e de aprendizagem, que tem um início, mas não tem um fim preestabelecido. Pode-se considerar como um processo cíclico, com sentido duplo, no qual a qualquer momento se pode voltar a alguma etapa, fazer melhoras, repensar, reconsiderar, adaptar. Esse processo avaliativo, quando é formativo, valoriza o aluno e estabelece para a sala de aula um novo contexto de ensino e de aprendizagem.

Conforme Hadji (1994), não há instrumento que esteja realmente especializado do ponto de vista da avaliação, todos os instrumentos que servem para provocar atividades são instrumentos tanto de aprendizagem como de avaliação. Cada docente precisa discutir e estudar formas de transformar suas práticas avaliativas em oportunidades de recolher informações para subsidiar os processos envolvidos, o processo de refletir sobre o processo de elaboração, aplicação e análise da produção recolhida apresenta-se como um caminho para essa transformação. Segundo Mendes, Trevisan e Buriasco (2012), para integrar atividades de ensino e avaliação, é imprescindível que o professor deixe de se pautar pela ideia de avaliação como um conjunto formado por provas e/ou trabalhos, usados apenas para medir os resultados do rendimento escolar, para transformá-los em instrumentos em favor da aprendizagem, que forneçam pistas sobre o processo de aprendizagem dos estudantes e das intervenções necessárias.

\section{Considerações finais}

Nessa pesquisa foi possível reconhecer, por meio do processo de (re)elaboração e correção de uma Prova Escrita de Matemática, uma oportunidade de refletir acerca da prática avaliativa que ocorreu, assim como acerca da prática avaliativa futura diante das ferramentas que fazem parte do dia a dia dos professores: a prova escrita, as grelhas de correção e a produção escrita dos alunos.

As reflexões oriundas de uma prática avaliativa podem trazer mudanças na realidade escolar, uma vez que o professor repensa sobre suas práticas (ações que ocorreram) ele pode então fazer uso de novas possibilidades, uso de instrumentos diversos de avaliação da prática avaliativa que está por vir (ações futuras), o desenvolvimento de saberes a partir e no exercício da profissão.

Elaborar um bom planejamento de avaliação (instrumentos, tarefas, grelhas de correções) é uma ação do professor. Tanto na elaboração das tarefas quanto das grelhas de correções, é necessário que todos os elementos sejam equilibrados. O professor tem que reconhecer que: não deve esperar que o planejado aconteça exatamente como está no papel. Durante o processo, ele vai precisar fazer alguns ajustes necessários, pois, por mais 
bem elaborado que seja esse processo, existem diversas circunstâncias que não podem ser previstas, e isso deve ser vivenciado e experienciado por ele.

Quando se está ciente dessas situações, as ações que o professor passa a realizar a são ações pedagógicas a favor da aprendizagem. Ele passa a ter consciência de que um plano de avaliação deve ser equilibrado a partir da utilização de uma diversidade de instrumentos para recolha de informações que subsidiem suas decisões.

\section{Referências}

BARLOW, M. Avaliação escolar: mitos e realidades. Porto Alegre: Artmed, 2006.

BURIASCO, R. L. C; FERREIRA, P. E. A; CIANI, A. B. Avaliação como Prática de Investigação (alguns apontamentos). Boletim de Educação Matemática, v. 33, p. 69-96, 2009.

BRASIL, Secretaria de Educação Fundamental. Parâmetros curriculares nacionais. introdução aos parâmetros curriculares nacionais. Brasília: MEC/SEF, 1998.

BRASIL. Ministério da Educação. Secretaria da Educação Básica. Base nacional comum curricular. Brasilia, DF, 2017.

DE LANGE, J. Mathematics, Insight and Meaning. Utrecht: OW \&OC, 1987.

DE LANGE, J. Framework for classroom assessment in mathematics. Utrecht: Freudenthal Institute and National Center for Improving Student Learning and Achievement in Mathematics and Science, 1999.

ESTEBAN, M. T. A avaliação no cotidiano escolar. In: ESTEBAN, M. T. et al. Avaliação: uma prática em busca de novos sentidos. 5 ed. Rio de Janeiro: DP\&A, 2003, p. 7-28.

FORSTER, C. A utilização da prova-escrita-com-cola como recurso à aprendizagem. 2015. 123f. Dissertação (Programa de Pós-Graduação em Ensino de Ciências e Educação Matemática) - Universidade Estadual de Londrina, Londrina, 2015.

HADJI, C. A avaliação, regras do jogo: das intenções aos instrumentos. Tradução Júlia Lopes Ferreira e José Manuel Cláudio. 4. ed. Portugal: Porto, 1994.

LUCKESI, C. C. O que é mesmo o ato de avaliar a aprendizagem? Pátio, Rio Grande do Sul, n.12, p. 6-11, 2000.

MATTA, A.E.R; SILVA, F.P.S; BOAVENTURA, E.M. Design-based research ou pesquisa de desenvolvimento: metodologia para pesquisa aplicada de inovação em educação do século XXI. Revista da FAEEBA - Educação e Contemporaneidade, Salvador, v. 23, n. 42, p. 23-36, 2014.

MENDES, M. T. Utilização da Prova em Fases como recurso para regulação da aprendizagem em aulas de cálculo. 2014. 275f. Tese de doutorado (Programa de PósGraduação em Ensino de Ciências e Educação Matemática) - Universidade Estadual de Londrina, 2014.

MENDES, M. T.; TREVISAN, A. L.; BURIASCO, R. L. C. Possibilidades de intervenção num contexto de ensino e avaliação em matemática. Revista de Educação Matemática e Tecnológica Iberoamericana, Pernambuco, vol. 3, n. 1, p.1-13, 2012. 
PEDROCHI JUNIOR, O. Avaliação como oportunidade de aprendizagem em Matemática. 2012. 56f. Dissertação (Programa de Pós-Graduação em Ensino de Ciências e Educação Matemática) - Universidade Estadual de Londrina, Londrina, 2012.

SMITH, M. S.; HILLEN, A.; HEFFERNAN, C. Student-constructed representations: Vehicles for helping teachers understand students' mathematical thinking. In: BLUME, Glendon; HEID, Mary Kathleen; SMITH, Margaret Schwan. 2001 Yearbook of the Pennsy/vania council of teachers of mathematics. The role of representation in the teaching and learning of mathematics, State College, PA: The Council of Teachers of mathematics, p. 65-69, 2001.

TARDF, M. Saberes docentes e formação profissional. 15. Ed. - Petrópolis, RJ: Vozes, 2013.

TREVISAN, A. L. Prova em fases e um repensar da prática avaliativa em Matemática. 2013. 168f. Tese de doutorado (Programa de Pós-Graduação em Ensino de Ciências e Educação Matemática) - Universidade Estadual de Londrina, Londrina, 2013.

VAN DEN HEUVEL-PANHUIZEN, M. Assessment and Realistic Mathematics Education. Freudenthal institute, Utrecht 1996. 